\title{
Time before isolating cystinotic leukocytes affects reliability of cystine determination
}

\author{
Meredith C. Fidler • Jon A. Gangoiti • \\ Jerry A. Schneider • Bruce A. Barshop
}

Received: 11 February 2009 /Revised: 6 March 2009/Accepted: 9 March 2009/Published online: 25 April 2009

(C) The Author(s) 2009. This article is published with open access at Springerlink.com

Sirs,

We are concerned that the manner in which leukocytes are prepared for the determination of cystine levels may cause imprecise results which could adversely affect the treatment of patients with cystinosis. Leukocyte cystine levels are used to diagnose cystinosis, monitor Cystagon therapy, and for multiple purposes in research studies. The determination of cystine in leukocytes is performed only in a small number of laboratories worldwide, one of which is the Cystine Determination Laboratory at the University of California San Diego (UCSD).

In the late 1970s, when the first cysteamine treatment trial was started, we evaluated ways to have blood shipped to the laboratory for the separation of leukocytes and the determination of intracellular cystine. It was determined that the leukocyte cystine level could only reliably be measured from samples that had been separated immediately after the blood was drawn. To ensure uniform preparation, our practice has been to ship reagents to point-of-care clinical laboratories, with precise instructions for sample preparation (http://biochemgen.ucsd.edu/cystinosis/), as in the published method [1]. Separated and lysed leukocyte samples are

This work was presented in part at the First International Cystinosis Research Symposium, Irvine, California, April 3, 2008. Pediatr Nephrol (2008) 23:1907-1923.

M. C. Fidler · J. A. Gangoiti · J. A. Schneider •

B. A. Barshop $(\square)$

Department of Pediatrics, UCSD School of Medicine,

University of California San Diego,

La Jolla, CA 92093-0830, USA

e-mail: bbarshop@ucsd.edu

M. C. Fidler · J. A. Gangoiti · J. A. Schneider · B. A. Barshop

Rady Children's Hospital-San Diego,

3020 Children's Way,

San Diego, CA, USA acidified, frozen and transported to our laboratory on dry ice for protein and cystine determinations.

Other laboratories accept heparinized whole blood shipped on wet ice for the determination of leukocyte cystine levels. The leukocytes are separated from the sample upon arrival at the laboratory, typically $24-48 \mathrm{~h}$ after the blood was drawn. This frees the point-of-care laboratory from the task of preparing the leukocytes, a procedure which is not complicated but which is time consuming and may be seen as an inconvenience.

Our laboratory therefore would naturally be interested in changing the procedure to accept whole blood. However, based on our experiences in the 1970s, we felt it was important to evaluate the stability of intracellular cystine in blood samples during storage and shipping. Until recently, the demanding cystine binding assay method used for the cystine assay made such an evaluation impractical, but a newer method using tandem mass spectrometry [3] has reduced sample analysis time drastically.

The aim of our small study was to evaluate whether intracellular cystine levels would be reliable if leukocyte separation from heparinized whole blood were delayed for up to $24-48 \mathrm{~h}$, as would be expected with express mail shipment.

Three cystinotic patients were enrolled into the study. Patients on Cystagon therapy were asked to discontinue therapy $24 \mathrm{~h}$ before participating. Blood was drawn from each subject, with aliquots anticoagulated in Li-heparin or Na-heparin. Blood was divided into 3-mL samples, and leukocytes were prepared in triplicate by the ACD-dextran method immediately after collection $(0 \mathrm{~h}$, baseline) or after being stored for $24 \pm 1$ or $48 \pm 1 \mathrm{~h}$ at either room temperature or $4^{\circ} \mathrm{C}$. All reagents for the separation were prepared by the UCSD Cystine Determination Laboratory. Protein content was determined using the Lowry method [3], and cystine content was measured using tandem mass spectrometry $[2$, 
Table 1 Leukocyte cystine levels ${ }^{\mathrm{a}}$ after the storage of whole blood for 24 or $48 \mathrm{~h}$ in Li- and Na-heparin (results averaged together) at room temperature or $4^{\circ} \mathrm{C}$ before separation of leukocytes

Leukocyte cystine levels

\begin{tabular}{lllll}
\hline Baseline & $24 \mathrm{~h}$ at $4^{\circ} \mathrm{C}$ & $24 \mathrm{~h}$ at RT & $48 \mathrm{~h}$ at $4^{\circ} \mathrm{C}$ & $48 \mathrm{~h}$ at $\mathrm{RT}$ \\
\hline $100.0 \pm 10.5$ & $120.5 \pm 39.6$ & $72.3 \pm 18.8$ & $123.26 \pm 66.4$ & $-{ }^{\mathrm{b}}$ \\
\hline
\end{tabular}

RT, Room temperature

${ }^{a}$ Leukocyte cystine levels are given as a percentage of the baseline value \pm the standard deviation

${ }^{\mathrm{b}}$ Leukocytes could not be separated in samples stored $48 \mathrm{~h}$ at RT

4]. Leukocyte cystine content was calculated as nanomoles half-cystine per milligram protein and is presented in Table 1 as the percentage of baseline value. Samples stored for 48 $\mathrm{h}$ at room temperature and collected in $\mathrm{Li}$ - and $\mathrm{Na}$-heparin, respectively, did not separate when mixed with ACD-dextran, and leukocytes could not be isolated from these samples. Leukocytes could be prepared from all other samples.

No differences were observed between $\mathrm{Li}$ - and $\mathrm{Na}-$ heparin, and the results for both anticoagulants were therefore combined. The levels determined at baseline and after storage for 24 and $48 \mathrm{~h}$ at $4^{\circ} \mathrm{C}$ and for $24 \mathrm{~h}$ at room temperature are shown in Table 1. Cystine levels in samples stored for $24 \mathrm{~h}$ at room temperature varied between 52 and $117 \%$ of baseline values. Even greater variations were measured when the samples were stored at $4^{\circ} \mathrm{C}$ for 24 h (37-214\%). After $48 \mathrm{~h}$, only samples stored at $4^{\circ} \mathrm{C}$ could be separated, and the cystine levels determined were between 52 and $240 \%$ of baseline values.

Although we tested only a small number of samples, we believe these results clearly show that results will be imprecise if leukocytes are not prepared immediately after heparinized blood is drawn. Accordingly, we encourage nephrologists treating cystinosis patients to take into account the time involved in storing and shipping samples prior to separating leukocytes for cystine determination.

We are hoping to expand this study and evaluate different agents which might stabilize leukocytes and obviate the need for immediate cell preparation, but we believe it important to share these results immediately with all pediatric nephrologists treating cystinosis patients.

Acknowledgement This work was supported by the Cystinosis Research Foundation.

Open Access This article is distributed under the terms of the Creative Commons Attribution Noncommercial License which permits any noncommercial use, distribution, and reproduction in any medium, provided the original author(s) and source are credited.

\section{References}

1. Greene AA, Jonas AJ, Harms E, Smith ML, Pellett OL, Bump EA, Miller AL, Schneider JA (1985) Lysosomal cystine storage in cystinosis and mucolipidosis type II. Pediatr Res 19:1170-1174

2. Dalton N, Turner C (2005) Leukocyte cystine: The key measurement. J Inherit Metab Dis 28:1206-1207

3. Lowry OH, Rosbrough NJ, Farr AL, Randall RJ (1951) Protein measurement with the Folin phenol reagent. J Biol Chem 193:265275

4. Fidler MC, Barshop BA, Gangoiti JA, Deutsch R, Martin M, Schneider JA, Dohil R (2007) Pharmacokinetics of cysteamine bitartrate following gastrointestinal infusion. Br J Clin Pharmacol 63:36-40 